\title{
KUALITAS HIDUP PASIEN STROKE DI POLIKLINIK RAWAT JALAN RUMAH SAKIT SWASTA YOGYAKARTA
}

\section{THE QUALITY OF LIFE OF THE STROKE PATIENTS IN OUTPATIENTS POLYCLINIC OF PRIVATE HOSPITAL IN YOGYAKARTA}

\author{
Hana Larasati ${ }^{1}$, Theresia Titin Marlina ${ }^{2 *}$ \\ ${ }^{* 1}$ Sekolah Tinggi IImu Kesehatan Panti Rapih, Jalan Tantular No. 401, Condongcatur, Depok, Sleman, \\ Daerah Istimewa Yogyakarta, email:hanalarasati96@gmail.com, Indonesia \\ ${ }^{2 \star}$ Sekolah Tinggi IImu Kesehatan Panti Rapih, Jalan Tantular No. 401, Condongcatur, Depok, Sleman, \\ Daerah Istimewa Yogyakarta, email: th77titin@gmail.com, Indonesia
}

\begin{abstract}
Background: stroke is a disorder of nervous system function that occurs suddenly and is caused by brain bleeding disorders that can affect the quality of life physical dimensions, social dimensions, psychological dimensions, environmental dimensions. Based on the result of Lumbu study (2015) the number of samples were 71 people collected data using the (WHOQOL-BREF). There were 56 people $(78,9 \%)$ had the poor quality of life of post stroke. The mean of post-stroke quality of life domain was physical domain $(45,27 \%)$, psychological domain $(49,87 \%)$, social relations domain $(48,15 \%)$ and environmental domain $(50.01 \%)$.

Objective: the purpose of the study was know the quality of life of the stroke patients in Outpatient Polyclinic of Private Hospital in Yogyakarta.

Methods: used descriptive quantitative by using questionnaire test of purposive sampling system based on patients who have been affected of ischemic or hemorrhagic stroke before, number 30 respondents.

Result: quality of life of stroke patient of medium physical dimension (67\%), psychological dimension (71\%), social dimension (67\%), dimension good environment $(63 \%)$.

Conclusion: the quality of life of stroke patients of physical dimension, psychological dimension, and moderate social dimension, while the quality of life of stroke patients were good environmental dimension.
\end{abstract}

Keywords: Hemorrhagic stroke, ischemic stroke, quality of life

\section{PENDAHULUAN}

Stroke adalah kematian mendadak jaringan otak yang disebabkan oleh kekurangan oksigen akibat pasokan darah yang terganggu. ${ }^{1}$ Stroke merupakan penyakit terbanyak ketiga setelah penyakit jantung dan kanker, serta merupakan kecacatan tertinggi di dunia. $^{2}$ Stroke menyebabkan disabilitas berat, gangguan emosi, dan ekonomi baik pasien maupun keluarga. ${ }^{3}$

Kualitas hidup penderita stroke mengalami gangguan atau hambatan karena adanya kecacatan fisik, kognitif, gangguan psikologis dan sosial. Di Amerika Serikat dalam menunjukkan adanya penurunan kualitas hidup pasca stroke yang meliputi aktivitas sehari-hari, pola komunikasi, aktivitas sosial, pekerjaan, istirahat, dan rekreasi. ${ }^{4}$ Beberapa penelitian menunjukkan penurunan kualitas hidup setelah menderita stroke. Salah satu studi mengatakan tidak ada perubahan fungsi fisik pada 3 dan 12 bulan paska stroke, namun terdapat penurunan kualitas hidup dan peningkatan level depresi. Depresi adalah tanda menurunnya level kualitas hidup. ${ }^{5}$

Menurut data WHO, ada 15 juta populasi setiap tahunnya di seluruh dunia dan terbanyak adalah usia tua dengan kematian rata-rata setiap 10 tahun antara 55 
dan 85 tahun. ${ }^{6}$ Menurut riset kesehatan 2014, prevalensi stroke di Indonesia mencapai 12,1 per 1000 orang. ${ }^{4}$ Prevalensi stroke di Yogyakarta pada tahun 2008 0,811\% penduduk. $^{2}$

Kualitas hidup pasien stroke dipengaruhi oleh status klinis pasien setelah menderita stroke. Status klinis tersebut diantaranya gangguan kognitif, inkontinensia urin dan lesi pada hemisfer. ${ }^{7}$

Hasil penelitian oleh Lombu di RSUD Gunungsitoli dengan jumlah sampel 71 orang menunjukkan bahwa gambaran kualitas hidup pasien stroke adalah buruk yaitu 56 orang (78,9\%). Nilai rata-rata domain kualitas hidup pasien stroke adalah domain fisik $(45,27 \%)$, domain psikologis $(49,87 \%)$, domain hubungan sosial $(48,15 \%)$, domain lingkungan $(50,01 \%)$, Dari keempat domain ini, domain lingkungan memiliki prosentase yang lebih banyak meskipun tidak signifikan. Yang dimaksud dengan domain lingkungan adalah rasa aman, ketersediaan dana, ketersediaaan informasi, kesempatan rekreasi, akses layanan kesehatan dan lingkungan tempat tinggal. ${ }^{8}$

Berdasarkan hasil studi pendahuluan di Rumah Sakit Swasta, total penderita stroke di Poliklinik Rawat Jalan per bulan tahun 2014 berjumlah 338, per bulan tahun 2015 berjumlah 397, per bulan tahun 2016 berjumlah 515, bulan Januari sampai September 2017 berjumlah 759 pasien. Dari data tersebut menunjukkan bahwa rata-rata jumlah pasien stroke setiap bulan adalah
502, rata-rata jumlah pasien stroke setiap minggu adalah 125, rata-rata jumlah pasien stroke setiap hari adalah 17 pasien.

Berdasarkan jumlah penderita yang semakin meningkat, penting diketahui secara ilmiah kualitas hidup penderita stroke pada aspek fisik, psikologis, sosial dan lingkungan di Poli Klinik Rawat Jalan Rumah Sakit Swasta Yogyakarta.

\section{BAHAN DAN CARA PENELITIAN}

Penelitian ini adalah penelitian kuantitatif dengan pendekatan cross secsional. Populasi dalam penelitian ini adalah semua pasien stroke yang sedang periksa di Poliklinik Rawat Jalan di salah satu rumah sakit swasta di Yogyakarta. Sampel dalam penelitian ini menggunakan ukuran kecil yaitu 30 penderita stroke dengan teknik purposive sampling yang memiliki kriteria bersedia menjadi responden, pasien yang sudah pernah terkena stroke iskemik dan atau hemoragik sebelumnya, bisa menulis, tidak mengalami amnesia atau gangguan daya ingat. Analisis menggunakan analisis deskriptif univariat dengan penyajian data menggunakan prosentase. Metode pengumpulan data dengan angket. Alat penelitian menggunakan kuisioner WHOQOL-BREF dengan 4 dimensi yang berisi 26 pertanyaan yang ditentukan dengan skor dalam skala likert berdasarkan kategori dengan point 1-5 yaitu (1) tidak sama sekali, (2) sedikit, (3) sedang, (4) sangat sering, (5) sepenuhnya. $^{9}$ 


\section{HASIL DAN PEMBAHASAN}

Tabel 1. Karakteristik Responden Pasien Stroke di Poliklinik Rawat Jalan, Rumah Sakit Swasta Yogyakarta Tahun 2017 $(\mathrm{n}=30)$

\begin{tabular}{lcc}
\hline $\begin{array}{l}\text { Karakteristik } \\
\text { Responden }\end{array}$ & Frekuensi & $\begin{array}{c}\text { Persentase } \\
(\%)\end{array}$ \\
\hline Usia & & \\
31-40 tahun & 2 & 6 \\
$41-50$ tahun & 3 & 10 \\
51-60 tahun & 12 & 40 \\
61-70 tahun & 8 & 27 \\
$\quad 71-80$ tahun & 5 & 17 \\
Jenis Kelamin & & \\
$\quad$ Laki-laki & 14 & 47 \\
$\quad$ Perempuan & 16 & 53 \\
Tingkat Pendidikan & & \\
Tidak sekolah & 1 & 3 \\
SD & 1 & 3 \\
SMP & 6 & 20 \\
SMA & 8 & 27 \\
D III & 3 & 10 \\
S I & 10 & 34 \\
S III & 1 & 3 \\
\hline
\end{tabular}

Sumber: Data Primer, 2017.

Berdasarkan Tabel 1, didapatkan data bahwa karakteristik usia pasien stroke meningkat pada usia lebih dari 51 tahun yaitu $84 \%$. Setelah usia 55 tahun, risiko stroke meningkat dua kali lipat setiap kurun waktu 10 tahun, hal ini disebabkan karena organ tubuh lansia mengalami proses degenerative termasuk pembuluh darah. ${ }^{10}$

Mayoritas pasien yang menderita stroke adalah wanita (53\%). Hal ini terjadi karena seiring bertambahnya usia wanita, hormon estrogen akan menurun yang akan menyebabkan rusaknya sel endotel dan memicu timbulnya plak pada pembuluh darah. Kondisi ini dapat menimbulkan penyakit darah tinggi bahkan stroke. ${ }^{10}$

Tingkat pendidikan responden lebih dari sebagian $53 \%$ adalah berpendidikan
SMA ke bawah, dan $47 \%$ berpendidikan tinggi (DIII,S1,S3). Tingkat pendidikan mempengaruhi pengetahuan terhadap faktor risiko stroke karena dengan pemahaman yang baik, terdapat upaya pencegahan yang dilakukan. ${ }^{11}$ Pengetahuan tentang penyakit dan pencegahan akan mempengaruhi motivasi individu untuk berperilaku sehat. ${ }^{12}$

Tabel 2. Kualitas Hidup Dimensi Fisik Pasien Stroke di Poliklinik Rawat Jalan, Rumah Sakit Swasta Yogyakarta Tahun 2017 $(\mathrm{n}=30)$

\begin{tabular}{lcc}
\hline Kualitas Hidup & Frekuensi & $\begin{array}{c}\text { Persentase } \\
(\%)\end{array}$ \\
\hline Sangat Buruk & 0 & $0 \%$ \\
Buruk & 1 & $3 \%$ \\
Sedang & 20 & $67 \%$ \\
Baik & 8 & $27 \%$ \\
Sangat Baik & 1 & $3 \%$ \\
\hline \multicolumn{1}{c}{ Total } & 30 & $100 \%$ \\
\hline
\end{tabular}

Sumber: Data Primer, 2017.

Berdasarkan Tabel 2, didapatkan bahwa kualitas hidup dimensi fisik pasien stroke $67 \%$ adalah berkualitas hidup sedang. Artinya bahwa lebih dari sebagian responden masih mampu melakukan aktivitas fisik dan mobilitas tanpa tergantung penuh pada oranglain.

Berdasarkan WHO, usia 80 tahun memasuki lanjut usia tua (old) dimana sesuai dengan fisiologis seseorang, semakin bertambahnya usia seseorang lebih rentan terhadap penyakit karena seiring peningkatan usia seseorang maka akan terjadi proses degeneratif pada semua sistem, salah satunya adalah sistem kardiovaskuler. Pembuluh darah menjadi kurang elastis bahkan kemungkinan terjadi penumpukan plak sehingga mempengaruhi percabangan 
pembuluh darah otak secara terus menerus akan mengganggu sirkulasi darah ke otak yang menyebabkan terjadinya iskemik dan akhirnya infark cerebral. ${ }^{10}$

Pada umumnya, kita mengetahui bahwa salah satu faktor risiko stroke adalah peningkatan tekanan darah. Sehingga dapat disimpulkan bahwa peningkatan usia secara tidak langsung mempengaruhi terjadinya stroke yang juga akan berpengaruh pada kualitas hidup seseorang. Hal ini sesuai dengan teori bahwa pasien yang berusia lebih dari 75 tahun mempunyai kualitas hidup buruk dibandingkan dengan pasien yang berusia muda. ${ }^{11}$

\section{Tabel 3. Kualitas Hidup Dimensi Psikologis Pasien Stroke di Poliklinik Rawat Jalan,} Rumah Sakit Swasta Yogyakarta Tahun 2017 $(n=30)$

\begin{tabular}{lcc}
\hline Kualitas Hidup & Frekuensi & $\begin{array}{c}\text { Persentase } \\
(\%)\end{array}$ \\
\hline Sangat Buruk & 0 & $0 \%$ \\
Buruk & 2 & $7 \%$ \\
Sedang & 22 & $71 \%$ \\
Baik & 6 & $19 \%$ \\
Sangat Baik & 1 & $3 \%$ \\
\hline \multicolumn{1}{c}{ Total } & 30 & $100 \%$ \\
\hline
\end{tabular}

Sumber: Data Primer, 2017.

Berdasarkan Tabel 3 didapatkan bahwa kualitas hidup dimensi psikologis pasien stroke menunjukkan $71 \%$ memiliki kualitas hidup sedang. Artinya lebih dari sebagian responden memiliki perasaan diri dan kepuasan diri yang cukup.

Prevalensi depresi pasca stroke berkisar antara 11-68\%, prevalensi ini semakin meningkat dengan meningkatnya umur penderita. Hal ini dikarenakan depresi dan emosi yang labil pada penderita stroke. ${ }^{12}$ Stroke dapat mengakibatkan penderitanya mengalami ketidakstabilan emosi sehingga menunjukkan respons emosi yang berlebihan atau tidak sesuai. ${ }^{13}$

Tabel 4. Kualitas Hidup Dimensi Sosial Pasien Stroke di Poliklinik Rawat Jalan, Rumah Sakit Swasta Yogyakarta Tahun 2017 $(n=30)$

Kualitas Hidup Frekuensi Persentase

(\%)

\begin{tabular}{lcc}
\hline Sangat Buruk & 1 & $3 \%$ \\
Buruk & 0 & $0 \%$ \\
Sedang & 20 & $67 \%$ \\
Baik & 7 & $23 \%$ \\
Sangat Baik & 2 & $7 \%$ \\
\hline \multicolumn{1}{r}{ Total } & 30 & $100 \%$ \\
\hline
\end{tabular}

Sumber: Data Primer, 2017.

Berdasarkan Tabel 4 didapatkan bahwa kualitas hidup dimensi sosial pasien stroke $67 \%$ memiliki kualitas hidup sedang. Yang dimaksud dimensi social ini adalah hubungan dengan orang lain, dukungan social atau keluarga. $67 \%$ responden dalam kategori kualitas hidup sedang, artinya bahwa mereka cukup mendapatkan dukungan sosial dari oranglain maupuin keluarga dan cukup memiliki relasi dengan orang lain.

Ada perubahan dalam cara hidup seperti merasa kesepian dan sadar akan kematian, hidup sendiri, perubahan dalam hal ekonomi, penyakit kronis, kekuatan fisik semakin lemah, terjadi perubahan mental, ketrampilan psikomotor berkurang, perubahan psikososial yaitu pensiun, akan kehilangan sumber pendapatan, kehilangan pasangan dan teman, serta kehilangan 
pekerjaan dan berkurangnya kegiatan yang dapat mempengaruhi kualitas hidupnya. ${ }^{14}$

Tabel 5. Kualitas Hidup Dimensi Lingkungan

Pasien Stroke di Poliklinik Rawat Jalan, Rumah Sakit Swasta Yogyakarta Tahun 2017 $(\mathrm{n}=30)$

\begin{tabular}{lcc}
\hline Kualitas Hidup & Frekuensi & $\begin{array}{c}\text { Persentase } \\
(\%)\end{array}$ \\
\hline Sangat Buruk & 0 & $0 \%$ \\
Buruk & 0 & $0 \%$ \\
Sedang & 10 & $34 \%$ \\
Baik & 19 & $63 \%$ \\
Sangat Baik & 1 & $3 \%$ \\
\hline \multicolumn{1}{c}{ Total } & 30 & $100 \%$ \\
\hline
\end{tabular}

Sumber: Data Primer, 2017.

Berdasarkan Tabel 5 didapatkan bahwa kualitas hidup dimensi lingkungan pasien stroke $63 \%$ berkualitas hidup baik. Berdasarkan hasil tersebut dapat diasumsikan bahwa penderita stroke ini memiliki lingkungan tempat tinggal yang nyaman, mudah mencapai akses pelayanan kesehatan, mendapatkan informasi yang cukup dan memiliki ketersediaan dana yang memadai. Hal ini berlawanan dengan hasil penelitian lain yang mengatakan bahwa penderita pasca stroke yang sebelumnya mampu bekerja dan mendapat penghasilan menjadi tidak mampu melakukannya lagi karena keterbatasan fisik yang dialami sehingga tidak bisa bekerja dan harus membebani keluarga dari segi finansial, dan berakibat beban ekonomi yang lebih tinggi bagi keluarga, dan hal ini akan mempengaruhi kualitas hidup mereka. ${ }^{15}$

\section{KESIMPULAN}

Sebanyak $67 \%$ responden memiliki kualitas hidup dimensi fisik sedang, sebanyak $71 \%$ responden memiliki kualitas hidup dimensi psikologis sedang, sebanyak 67\% responden memiliki kualitas hidup dimensi sosial sedang, sebanyak $63 \%$ responden memiliki kualitas hidup dimensi lingkungan baik.

Saran bagi peneliti selanjutnya untuk meneliti kualitas hidup pasien stroke dengan jumlah responden yang lebih banyak sesuai dengan populasi yang ada di lokasi penelitian.

\section{TERIMA KASIH}

1. Chatarina Setya Widyastuti.,M.Kep., Ns.Sp.Kep.,MB, Ketua STIKes Panti Rapih Yogyakarta

2. Responden penelitian

\section{KEPUSTAKAAN}

1. Dinata, C. A.,Safrita, Y., \& Sastri, S. Gambaran Faktor Risiko dan Tipe Stroke pada Pasien Rawat Inap di Bagian Penyakit Dalam RSUD Kabupaten Solok Selatan. Juni 2012, Hal.2

2. Wibawa, E. A., Kuntjoro, T., \& Pinzon, R. T. Kepuasan Pasien Stroke Peserta JKN di RS Lestari Raharja dan RSUD Muntilan Kabupaten Magelang. 2016, Hal. 257.

3. Kulshreshtha A, Anderson LM. Stroke in South Asia: A Systematic Review of Epidemiologic Literature from 1980-2010. Neuroepidemiology. 2012.

4. Bays, C. L. Older Adults' Description of Hope After a Stroke. Rehabilitation Nursing. 2001.

5. Kwok T, Lo RS, dkk. Quality of Life of Stroke Survivors: A 1-year follow-up study. Arch Phys Med Rehabil. 2006. 
6. Setiawan, R., Munadi, \& Hidayat, A.Studi

Perbandingan Perbedaan Sudut

Evacuated Glass Tube pada Sistem

Evacuated Solar Water Heater Terhadap

Panas dan Gaya Pembebanan sebagai

Pemanas Air untuk Kolam Terapi

Penderita Stroke. 2012. Hal 1005

7. Patel, M.D., McKevitt,C., Rudd, A. G., \& Wolfe, C. D. Clinical Determinants of Long-Term Quality of Life After Stroke. Age and Ageing. Maret 2007.

8. Lombu, K. E. Gambaran Hidup Pasien Paska Stroke di RSUD Gunungsitoli. University of Sumatera Utara Institutional Repository (USU-IR). 10 September 2015.

9. Panjaitan, R.B. Kualitas Hidup Pasien Kanker Payudara yang Dirawat di Rumah Sakit Umum Pusat Hati Adam Malik Medan. Skripsi Fakultas Keperawatan Universitas Sumatra Utara. 2015. Hal 2225

10. Prince, S. A., Wilson, L. M. Patofisiologi: Konsep Klinis Proses-proses Penyakit. Dublin: EGC. 2006.

11. Steigelman, L. K., Kimble, L. P., Dunbar, S., Sowell, R. L., \& Bairan, A. Religion, Relationships and Mental Health in Midlife Woman Following Acute Myocardial Infarction. Issues in Mental Health Nursing. 2006, Hal. 171.

12. Suwantara, J. R. Depresi pasca-stroke : epidemiologi, rehabilitasi, dan psikoterapi. Jurnal Kedokteran Trisakti. OktoberDesember 2004, Hal. 151

13. Rambe, A. S. Stroke: Sekilas tentang definisi, penyebab, efek, dan faktor risiko. Departemen Neurologi FK-USU/RSUP H. Adam Malik, Medan. 2015, Hal. 196.

14. Nugroho. Keperawatan Gerontik \& Geriatrik. Jakarta; Penerbit Buku Kedokteran EGC; 2008.

15. Handayani, D. Y., Dewi, D. E. Analisis Kualitas Hidup Penderita dan Keluarga Pasca Serangan Stroke (Dengan Gejala Sisa). Phsyco Idea. 2009. 